\title{
Erratum to: Onset of significant pelagic carbonate accumulation after the Carnian Pluvial Event (CPE) in the western Tethys
}

\author{
Nereo Preto $\cdot$ Helmut Willems $\cdot$ Chiara Guaiumi • \\ Hildegard Westphal
}

Published online: 12 November 2013

(c) Springer-Verlag Berlin Heidelberg 2013

\section{Erratum to: Facies (2013) 59:891-914 \\ DOI 10.1007/s10347-012-0338-9}

There is a mistake in the calculation of our estimate of bias in the point-counting of small spheres in thin-sections (section "Stratigraphic distribution of calcispheres"; fig. 12 and table 2 in original article). An amended version of the mistaken text, a corrected figure, and a re-calculated table are provided in this erratum.

\section{Point-counting of small spheres in thin-sections}

In a thin-section with a discrete thickness, spheres located on different plains are counted simultaneously (fig. 12a in original article), so the occurrence of a sphere under the crucible is more probable. This equals to the counting of a "equivalent solid" constituted by the sphere plus a cylinder with the diameter of the sphere, and the height coinciding

The online version of the original article can be found under doi:10.1007/s10347-012-0338-9.

\footnotetext{
N. Preto $(\bowtie) \cdot$ C. Guaiumi

Department of Geosciences, University of Padova,

Via Gradenigo, 6, 35131 Padua, Italy

e-mail: nereo.preto@unipd.it

N. Preto $\cdot$ H. Westphal

Leibniz Center for Marine Tropical Ecology, Bremen, Germany

H. Willems

Department of Earth Sciences, University of Bremen,

Bremen, Germany
}

with the thickness of the thin-section (fig. 12a in original article). The volume of this solid is larger than that of the sphere, being:

$V=(4 / 3) \pi r^{3}+\pi r^{2} h$

where $V$ is the volume of the equivalent solid, $r$ is the radius of the calcisphere and $h$ is the thickness of the thinsection. The first term of the expression is the volume of the sphere with radius $r$, the second term (cylinder) falls to zero for an ideal thin-section without thickness. The bias in point counting of small spheres can be calculated, provided that the average radius of spheres is known, as the ratio between the equivalent solid and the ideal sphere:

$\left((4 / 3) \pi r^{3}+\pi r^{2} h\right) /(4 / 3) \pi r^{3}=1+3 h / 4 r$

which is the reciprocal of expression 11.7 of Chayes (1956, p. 99). The Carnian-Norian calcispheres of our study can be conveniently modeled as spheres with an average diameter of $20-22 \mu \mathrm{m}$ (fig. 10 in original article), thus the proposed correction can be applied. Note that the bias for $20 \mu \mathrm{m}$ spheres in a standard $(30 \mu \mathrm{m})$ thin-section is huge, the proportion of such spheres being overestimated by more than $200 \%$. A strong bias should be expected each time the proportion of small objects is evaluated via standard point-counting (Chayes 1956).

\section{References}

Chayes F (1956) Petrographic modal analysis-an elementary statistical appraisal. Wiley, New York

Erba E, Tremolada F (2004) Nannofossil carbonate fluxes during the Early Cretaceous: phytoplankton response to nitrification episodes, atmospheric $\mathrm{CO}_{2}$, and anoxia. Paleoceanography 19:PA1008 1-18 


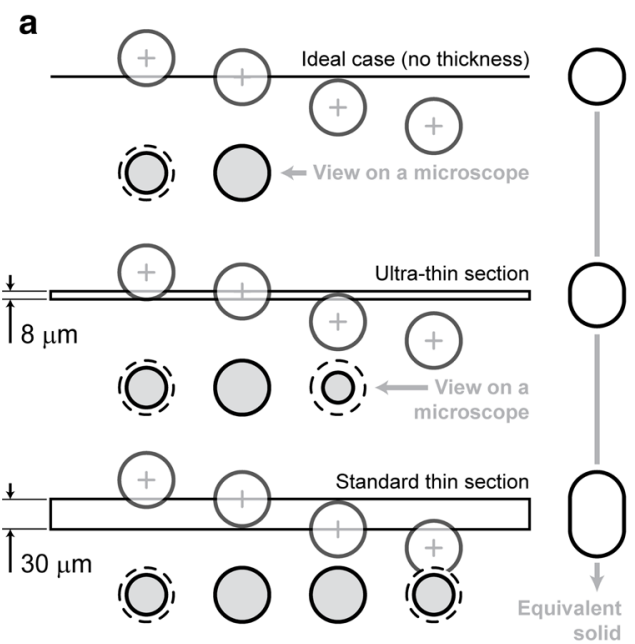

Fig. 12 Illustration of bias in point-counting of small objects (spheres in this case) and its correction. a Bias in counting spheres with a radius of $30 \mu \mathrm{m}$, for an ideal thin-section of no thickness, for an ultra-thin-section of $8 \mu \mathrm{m}$ (Erba and Tremolada 2004) and for a standard thin section of $30 \mu \mathrm{m}$. A sphere is seen with its full diameter under the microscope, when its centroid is within the thickness of the thin-section. In the ideal case of a thin-section with no thickness, the case of a great circle lying on the plane of the thin-section is a degenerate one. In this case, the point-counting of small spheres yields an accurate estimate of the proportion of rock volume they

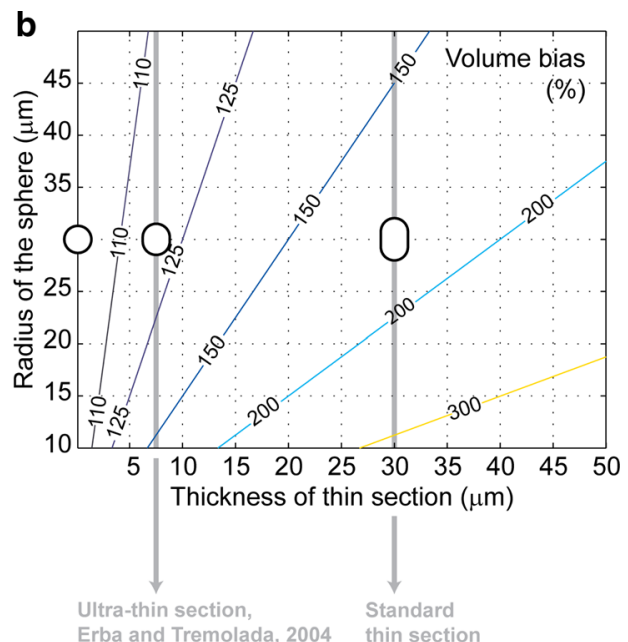

occupy. Point-counting spheres in a thin-section with some thickness (i.e., any real thin-section) is equivalent to point-counting "equivalent solids" (on the right) in a ideal thin-section with no thickness. This implies that the volume of small spheres is overestimated. b Bias as function of the thickness of the thin-section and of the radius of the spheres. Given a standard thin-section and spheres with a diameter of $60 \mu \mathrm{m}$ (the case illustrated in a), the volume occupied by spheres is strongly overestimated (175\% of real volume). Spheres with smaller diameter (as in the case of this study) imply a much larger bias

Table 2 Relative abundances (in percent) of components in carbonate facies of Pizzo Mondello, after correction of the volume of calcispheres (for an average diameter of $20 \mu \mathrm{m}$ and a thin-section thickness of $30 \mu \mathrm{m}$, see Fig. 12 of this erratum)

\begin{tabular}{lllllllll}
\hline & Matrix & Calcispheres & T.S. Bivalves & Radiolarians & Forams & Ammon. & Undeterm. & N, mean \\
\hline F.A. A & 51.39 & 4.12 & 8.29 & 28.48 & 0.20 & 0.02 & 6.63 & 672 \\
F.A. B & 45.87 & 4.92 & 7.73 & 33.40 & 0.25 & 0.06 & 7.76 \\
F.A. B/C, C & 44.33 & 8.91 & 8.78 & 31.22 & 0.22 & 0.03 & 6.51 \\
All section* & 50.15 & 5.64 & 8.06 & 29.19 & 0.22 & 0.03 & 6.71 \\
\hline
\end{tabular}

Correction implies a significant (325\%) reduction of the volume of calcispheres; the residual volume was distributed proportionally between the other components. Results of point counting before correction are given in table 1 in original article 